\title{
Synthesis and Catalytic Performance of Al-MCM-48 and Ti-MCM-48
}

\author{
Zhao Zhixi ${ }^{1}$, Liming Zhang ${ }^{1}$, Ping Chen $^{1}$ and Yan Kun ${ }^{*}, 2$ \\ ${ }^{1}$ Key Laboratory of Pollution Monitoring and Control, Xinjiang Normal University, Urumqi 830054, China \\ ${ }^{2}$ Yantai Institute of Coastal Zone Research, Chinese Academy of Sciences, Yantai, Shandong 264003, China
}

\begin{abstract}
Mesoporous sieves MCM-48 with hetero atom were synthesized by adding aluminum and titanium sources through hydrothermal method. The results showed that MCM-48 could be synthesized respectively by adjusting exactly the alkalinity of synthesis gel. The conversion rate of DIPB on Al-MCM- 48 increased to $80 \%$ after $9 \mathrm{~h}$ and the selectivity of IPB was $97 \%$. The conversion rate of styrene on Ti-MCM-48 increased to $9 \%$ after $8 \mathrm{~h}$ and the selectivity of benzaldehyde was $85 \%$. The available active sites, which were introduced by aluminum and titanium atoms, were effectively utilized for catalyst reaction due to the presence of mesopores in Al-MCM-48 and Ti-MCM-48.
\end{abstract}

Keywords: Al-MCM-48, phase transition, styrene oxidation, Ti-MCM-48, transalkylation.

\section{INTRODUCTION}

The mesoporous materials have extensive application due to their excellent structural ordering, tunable pore size and high surface area and pore volume [1-3]. MCM-41, MCM48 and MCM-50 are members of M41S family which have one-dimensional pore, three-dimensional pore and no pore structure respectively [4]. Due to the active sites' being accessible to the reactants pore, MCM-48 structure has more advantages of catalytic applications than the other materials [5].

In order to make the materials catalytically active, other elements have to be incorporated into the siliceous framework. Al-MCM-48 can be used as heterogeneous acid catalysts, especially for reactions involving bulky molecules which require moderate acid strength [6]. In post-synthesized MCM-48 containing hetero atoms, significant destruction of mesopore structure and short life of active sites are the great drawbacks [7]. Incorporation of hetero atoms by direct syntheses is needed urgently. It is well known that the $\mathrm{pH}$ value of the micelle solution plays a significant role in the formation of high quality mesoporous molecular sieves [4]. Most of the $\mathrm{pH}$-dependencies have been outlined concerning hydrolysis and polycondensation of inorganic framework builder [8]. However, the effect of base concentration in the micellar solution on the formation of MCM-48 with aluminum and titanium atoms incorporation is rare in previous research. We conducted systematic study for finding the influence of the alkalinity of synthesis gel on the structure of mesoporous materials. Then we chose transalkylation of diisopropylbenzene (DIPB) with benzene and oxidation of styrene with $\mathrm{H}_{2} \mathrm{O}_{2}$ to assess the catalytic performance of the obtained Al-MCM-48 and Ti-MCM-48 respectively.

*Address correspondence to this author at the Yantai Institute of Coastal Zone Research, Chinese Academy of Sciences, Yantai, Shandong 264003, China; Tel: 13579277365; E-mail: happyxjway@163.com

\section{MATERIALS AND METHODS}

Synthesis mixture of Al-MCM-48 was prepared as follows: Al source and Si source were added to the solution of cetyltrimethyl-ammonium bromide (CTAB, First Chemical Co., Beijing), NaOH (First Chemical Co., Shanghai) and deionized water. The molar composition of the above mixture was $n\left(\mathrm{SiO}_{2}\right): n(\mathrm{CTAB}): n\left(\mathrm{Na}_{2} \mathrm{O}\right): n$ $\left(\mathrm{H}_{2} \mathrm{O}\right): n\left(\mathrm{Al}_{2} \mathrm{O}_{3}\right)=1.00: 0.156: x: 55.6: 0.025$. The $\mathrm{Al}$ source was aluminum sulfate $\left(\mathrm{Al}_{2}\left(\mathrm{SO}_{4}\right)_{3}\right.$, First Chemical Co., Beijing). The Si source was tetraethyl orthosilicate (TEOS, First Chemical Co., Beijing). This solution was stirred at 30 ${ }^{\circ} \mathrm{C}$ for $1 \mathrm{~h}$. After that, the mixture was placed in a autoclave at $100{ }^{\circ} \mathrm{C}$ for 3 days. The solid product was recovered and calcined at $550{ }^{\circ} \mathrm{C}$ in air $\left(5^{\circ} \mathrm{C} / \mathrm{min}\right)$ for $6 \mathrm{~h}$. The synthesis mixture of Ti-MCM- 48 was prepared similarly by adding $\mathrm{Ti}$ source and $\mathrm{Si}$ source into the mixture solution of CTAB, $\mathrm{NaOH}$ and $\mathrm{H}_{2} \mathrm{O}$. The molar composition of the above mixture was $n\left(\mathrm{SiO}_{2}\right): n(\mathrm{CTAB}): n\left(\mathrm{Na}_{2} \mathrm{O}\right): n\left(\mathrm{H}_{2} \mathrm{O}\right): n$ $\left(\mathrm{TiO}_{2}\right)=1.00: 0.156: x: 55.6: 0.02$. The Ti source $(w$ $\left.\left(\mathrm{TiCl}_{4}\right)=63.3 \%\right)$ was obtained by dissolving titanium tetrachloride $\left(\mathrm{TiCl}_{4}\right.$, First Chemical Co., Beijing) in isopropanol (First Chemical Co., Shanghai). The Si source was the same as TEOS that was applied in the synthesis of Al-MCM-48. This solution experienced the same treatment process like Al-MCM-48 to produce calcined Ti-MCM-48.

The prepared Al-MCM-48 was tested for transalkylation of DIPB with benzene in a fixed bed reactor at $523 \mathrm{~K}$ under 20 atmospheric pressures. The weight hourly space velocity (WHSVN) was $3.0 \mathrm{~h}^{-1}$. The benzene to DIPB molar ratio was 2.33:1. The reaction mixture of benzene and DIPB was injected using a syringe pump. Reaction products were collected and analyzed with an Agilent 6820 gas chromatograph. The oxidation of styrene with $\mathrm{H}_{2} \mathrm{O}_{2}$ was examined as following reaction conditions. Catalyst $(1 \mathrm{~g})$, styrene $(10 \mathrm{~mL}), \mathrm{H}_{2} \mathrm{O}_{2}(30 \%$ aqueous solution, $9.7 \mathrm{~g})$ and acetonitrile $(30 \mathrm{~mL})$ were placed into a reaction vessel. The resulting mixture was stirred at $65{ }^{\circ} \mathrm{C}$ for $8 \mathrm{~h}$. Reaction 
products were collected and analyzed with GC 7890F (Techcomp Scientific Instrument Co., Ltd., China).

\section{RESULTS AND DISCUSSION}

Fig. (1) shows the variety of XRD patterns of samples prepared in aluminum sulfate source in a series of $\mathrm{Si} / \mathrm{Na}_{2} \mathrm{O}$ ratio $(x=0.238-0.350)$. At the lowest $\mathrm{Si} / \mathrm{Na}_{2} \mathrm{O}$ ratio $(x=0.238)$, indexed peaks of synthesized samples were associated with the lamellar symmetry, mixed with a weak peak associated with the cubic symmetry. Then at $x=0.301$, synthesized samples showed the majority of peaks associated with the cubic symmetry, with a weak peak of the lamellar symmetry remained. Added $\mathrm{Si} / \mathrm{Na}_{2} \mathrm{O}$ ratio further to $x=0.325$, synthesized samples showed identical peaks associated with the cubic symmetry without any other peaks of impure phase existed. When $\mathrm{Si} / \mathrm{Na}_{2} \mathrm{O}$ ratio was added to $x=0.350$, the peaks associated with the hexagonal symmetry showed the production of MCM-41 under the $\mathrm{Si} / \mathrm{Na}_{2} \mathrm{O}$ ratio.

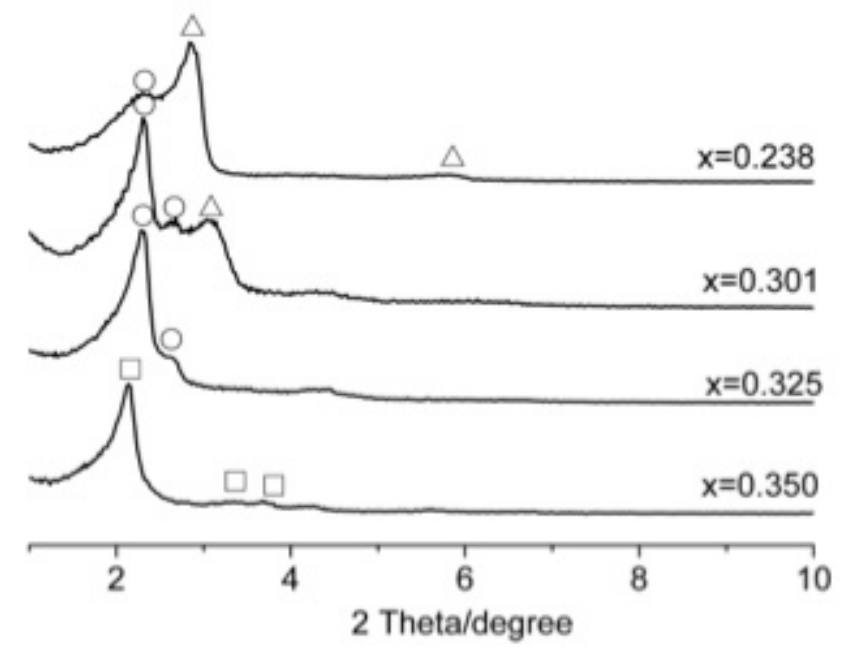

Fig. (1). XRD patterns of samples synthesized with aluminum sulfate $\left(\mathrm{n}\left(\mathrm{SiO}_{2}\right): \mathrm{n}(\mathrm{CTAB}): \mathrm{n}\left(\mathrm{Na}_{2} \mathrm{O}\right): \mathrm{n}\left(\mathrm{H}_{2} \mathrm{O}\right): \mathrm{n}\left(\mathrm{Al}_{2} \mathrm{O}_{3}\right)=1.00\right.$ : $0.156: x: 55.6: 0.025)$. Square, circle and triangle indicate MCM-41, MCM-48 and MCM-50 respectively.

Fig. (2) shows the variety of XRD patterns of samples prepared in titanium tetrachloride source in a series of $\mathrm{Si} / \mathrm{Na}_{2} \mathrm{O}$ ratio $(x=0.225-0.244)$ at $\mathrm{Si} / \mathrm{Ti}=50$. Compared with the XRD patterns of samples prepared at $\mathrm{Si} / \mathrm{Ti}=50$, the range of the ratio of $\mathrm{Si} / \mathrm{Na}_{2} \mathrm{O}$ in which phase transition happened becomes much narrower, although the sequence of phase transition is in the same way. Moreover, the weaker peaks associated with the cubic symmetry also suggest the poor quality of synthesized Ti-MCM-48 at lower $\mathrm{Si} / \mathrm{Ti}$ ratio.

At different $\mathrm{Si} / \mathrm{Al}$ ratios, catalytic performances of $\mathrm{Al}$ MCM-48 were evaluated for transalkylation of DIPB with benzene. The conversion rates of DIPB and selectivity of IPB are shown in Figs. $(3,4)$ respectively. It could be seen that the conversion rate of DIPB decreased from $90 \%$ to $80 \%$ after a reaction time of $9 \mathrm{~h}$ over the Al-MCM- 48 with Si/Al $=60$. However, for Al-MCM-48 with $\mathrm{Si} / \mathrm{Al}=40$ and 20, the conversion rates of DIPB increased from $66 \%$ to $80 \%$ after 9 $\mathrm{h}$ under the same reaction conditions. The selectivity of IPB on Al-MCM-48 were very high at $\mathrm{Si} / \mathrm{Al}=20$ and 40 , which were about $97 \%$ in whole $9 \mathrm{~h}$ reaction time. These results indicated that Al-MCM-48 had good activity and stability for the transalkylation of DIPB with benzene and its activity and stability increased at high $\mathrm{Si} / \mathrm{Al}$ ratios.

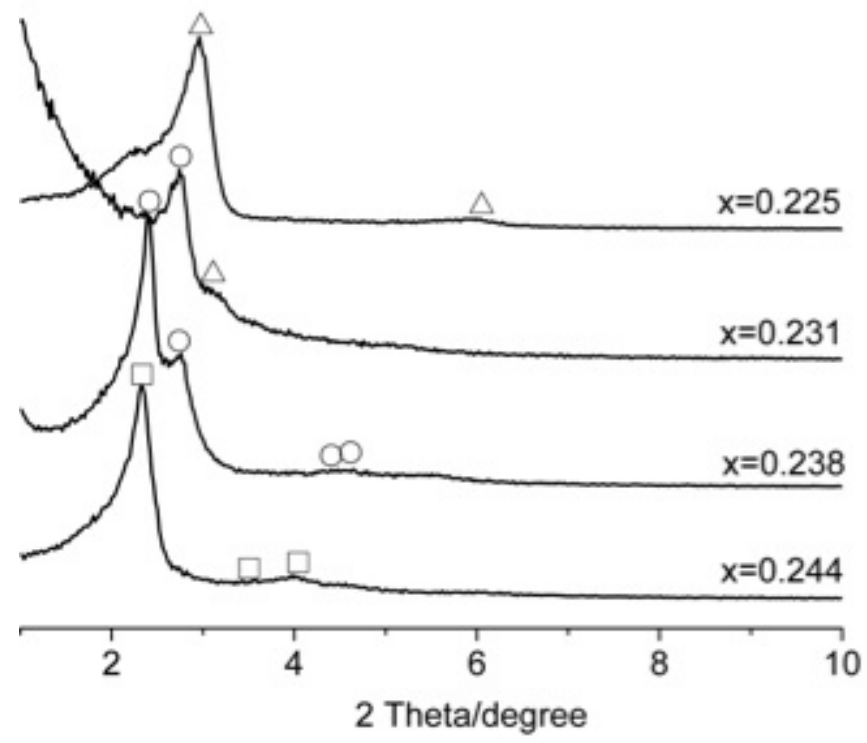

Fig. (2). XRD patterns of samples synthesized with titanium tetrachloride $\left(\mathrm{n}\left(\mathrm{SiO}_{2}\right): \mathrm{n}(\mathrm{CTAB}): \mathrm{n}\left(\mathrm{Na}_{2} \mathrm{O}\right): \mathrm{n}\left(\mathrm{H}_{2} \mathrm{O}\right): \mathrm{n}\left(\mathrm{TiO}_{2}\right)=\right.$ $1.00: 0.156: x: 55.6: 0.02)$. Square, circle and triangle indicate MCM-41, MCM-48 and MCM-50 respectively.

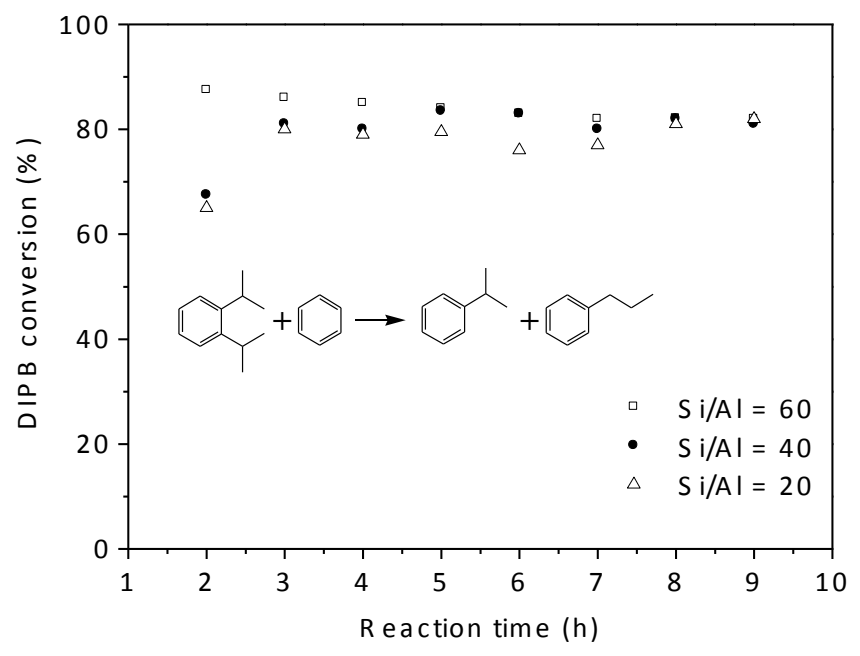

Fig. (3). DIPB conversions in transalkylation with benzene on AlMCM-48 at different $\mathrm{Si} / \mathrm{Al}$ ratios in a fixed bed reactor at $523 \mathrm{~K}$ under 20 atmospheric pressures. The weight hourly space velocity (WHSVN) was $3.0 \mathrm{~h}-1$. The benzene to DIPB molar ratio was 2.33:1.

It is widely accepted that the accessibility of catalytic active sites plays a critical role in some diffusion-controlled reactions [10]. As has been reported and confirmed in previous studies, the available active sites in the mesoporous materials are effectively utilized. Hence the high conversion of DIPB could be attributed to the enhanced accessibility of catalytically active sites to reactant molecules on Al-MCM48. The acid properties of catalyst (acid type, acid amount, acid strength and distribution, etc.), the nature of the hole, (channel structure and size, pore size distribution, specific surface area, etc.) and the nature of the crystal (crystal type, structure, $\mathrm{Si} / \mathrm{Al}$ ratio, grain size, etc.) determined the catalytic activity of Al-MCM-48 for transalkylation [9]. The 
conversion rate of DIPB transalkylation reaction was directly related to the amount of $\mathrm{B}$ acid catalyst. Only when the amount of $\mathrm{B}$ acid reached to a certain concentration, the catalyst was not active.

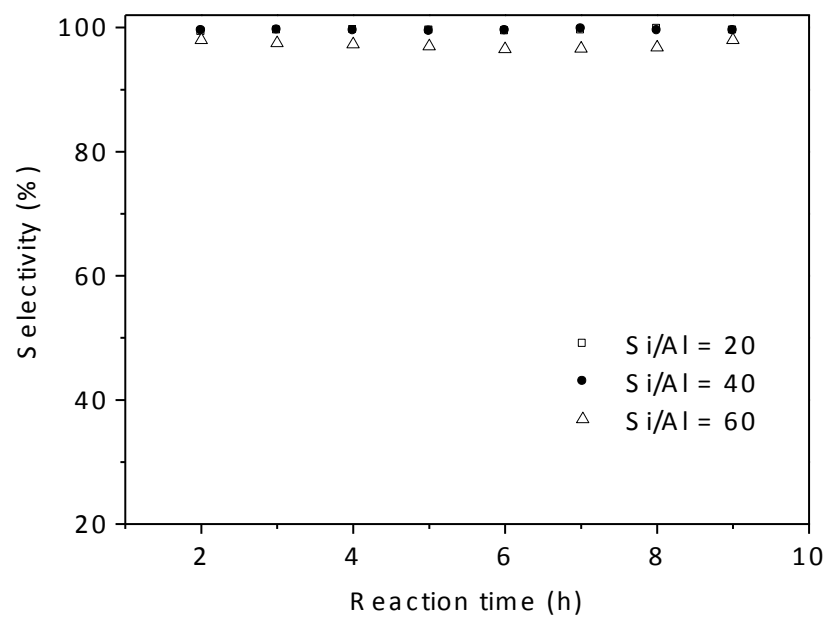

Fig. (4). IPB selectivity in DIPB transalkylation with benzene on Al-MCM-48 at different Si/Al ratios in a fixed bed reactor at $523 \mathrm{~K}$ under 20 atmospheric pressures. The weight hourly space velocity (WHSVN) was $3.0 \mathrm{~h}-1$. The benzene to DIPB molar ratio was 2.33:1.

The catalytic performances of Ti-MCM-48 with different $\mathrm{Si} / \mathrm{Ti}$ ratios were evaluated for oxidation of styrene with $\mathrm{H}_{2} \mathrm{O}_{2}$. The conversion rates of styrene and selectivity of the products are shown in Figs. $(\mathbf{5}, \mathbf{6})$. It could be seen that styrene conversion increased from $1 \%$ to $7 \%$ after a reaction time of $8 \mathrm{~h}$ over the Ti-MCM-48 with $\mathrm{Si} / \mathrm{Ti}=100$. However, for Ti-MCM-48 with $\mathrm{Si} / \mathrm{Ti}=50$, the conversion of styrene increased from $1.1 \%$ to $9 \%$ after $8 \mathrm{~h}$ under the same reaction conditions. These results indicated that Ti-MCM-48 had good catalytic activity for the oxidation of styrene with $\mathrm{H}_{2} \mathrm{O}_{2}$ at two $\mathrm{Si} / \mathrm{Ti}$ ratios and catalytic activity was increased with the content of $\mathrm{Ti}$ in Ti-MCM-48. For Ti-MCM-48 with $\mathrm{Si} / \mathrm{Ti}=50$, the selectivity of benzaldehyde and phenyloxirane increased from $75 \%$ and $0.1 \%$ to $85 \%$ and $5 \%$ respectively during a reaction time of $8 \mathrm{~h}$. The selectivity of phyenylacetaldehyde decreased from $25 \%$ to $10 \%$ at the same time. This suggested that benzaldehyde was the main product for oxidation of styrene with $\mathrm{H}_{2} \mathrm{O}_{2}$ on Ti-MCM-48. The available active sites, which were introduced by titanium atoms, were effectively utilized for oxidation of styrene to produce benzaldehyde on Ti-MCM-48.

\section{CONCLUSION}

Under the influence of CTAB, TEOS, sodium hydroxide and different aluminum or titanium sources, the mesoporous sieves MCM-48 with hetero atoms were synthesized by adjusting the alkalinity of the synthesis gel exactly. AlMCM-48 and Ti-MCM-48 showed promising catalytic performance in transalkylation of DIPB with benzene and oxidation of styrene with $\mathrm{H}_{2} \mathrm{O}_{2}$ respectively. The conversion rates of DIPB increases to $80 \%$ after $9 \mathrm{~h}$ on Al-MCM-48. The selectivities of IPB were very high at $\mathrm{Si} / \mathrm{Al}=20$ and 40 , which were about $97 \%$. For Ti-MCM-48 with $\mathrm{Si} / \mathrm{Ti}=50$, the conversion rate of styrene increased to $9 \%$ after $8 \mathrm{~h}$ and the selectivity of benzaldehyde was $85 \%$.

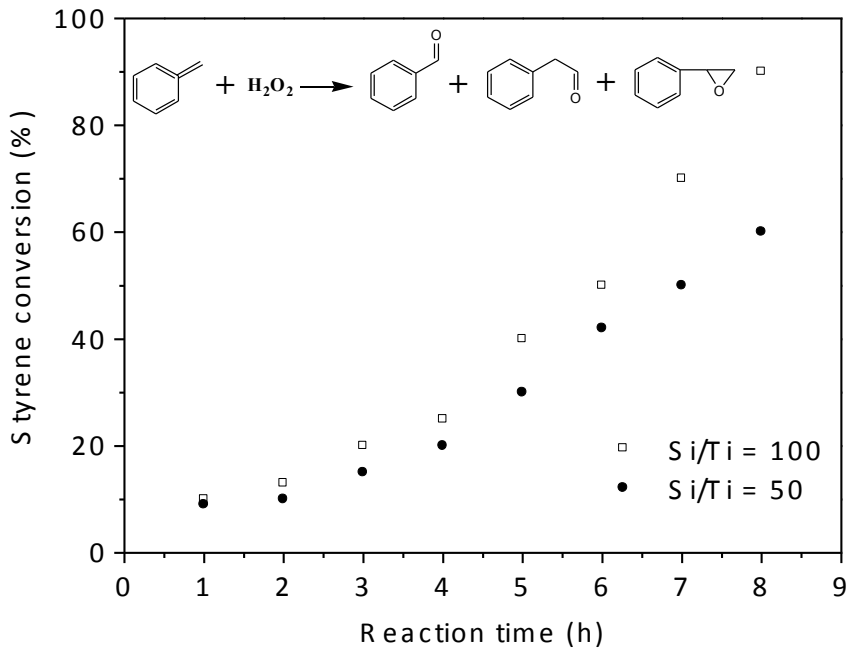

Fig. (5). Styrene conversions in oxidation on Ti-MCM-48 at different $\mathrm{Si} / \mathrm{Ti}$ ratios with $1.0 \mathrm{~g}$ catalyst, $10 \mathrm{~mL}$ styrene, $9.7 \mathrm{~g} \mathrm{H}_{2} \mathrm{O}_{2}$ (30\% aqueous solution) and $30 \mathrm{~mL}$ acetonitrile.

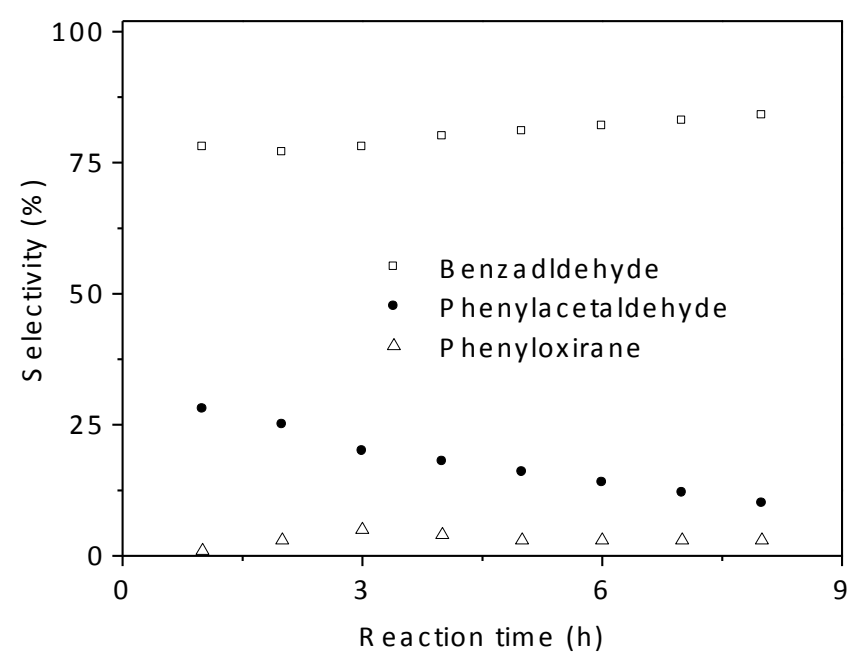

Fig. (6). Benzaldehyde, phyenylacetaldehyde, phenyloxirane selectivity in styrene oxidation on Ti-MCM-48 at different $\mathrm{Si} / \mathrm{Ti}$ ratios with $1.0 \mathrm{~g}$ catalyst, $10 \mathrm{~mL}$ styrene, $9.7 \mathrm{~g} \mathrm{H}_{2} \mathrm{O}_{2}(30 \%$ aqueous solution) and $30 \mathrm{~mL}$ acetonitrile.

\section{ABOUT THE AUTHORS}

First Author Zhao zhixi, University lecturer of Xinjiang Normal University, Ph.D. The author's major is synthesis and application of materials. 7 papers received by EI or SCI and 1 patents had been published.

Second Author Zhang liming, master degree in materials in Xinjiang Normal University. The author's major is Materials Engineering.

Third Author Chen ping, professor of Xinjiang Normal University, Ph.D. The author's major is synthesis and application of materials.

Four Author Yan kun, professor of Yantai Institute of Coastal Zone Research, Chinese Academy of Sciences, Ph.D. The author's major is synthesis and application of materials. 


\section{CONFLICT OF INTEREST}

The authors confirm that this article content has no conflict of interest.

\section{ACKNOWLEDGEMENTS}

This work was financially supported by the National Natural Science Foundation of China (41203071) and the Natural Science Foundation of Xinjiang Uygur Autonomous Region (2012211B17).

\section{REFERENCES}

[1] Komarneni S, Pidugu R, Menon VC. Water adsorption and desorption isotherms of silica and alumina mesoporous molecular sieves. J Porous Mat 1996; 3: 9-106.

[2] Hamoudi S, Saad R, Belkacemi K. Modeling breakthrough curves for adsorption of monobasic phosphate using ammoniumfunctionalized MCM-48. Separ Sci Technol 2013; 48: 2099-107.

[3] Song L, Wang Y, Zhu L. Surface Modification to Improve the Sorption Property of U(VI) on Mesoporous Silica. J Radioanalyt Nuclear Chem 2014; 299: 1589-95.
[4] Jeong K, Jeong S. Aromatic reduction of residue oil of naphtha cracking over bimetallic $\mathrm{Pt}-\mathrm{Pd}$ catalysts supported on mesoporous molecular sieve. Res Chem Intermed 2008; 34: 693-701.

[5] Yu F, Ji D, Nie Y. Study on the pyrolysis of cellulose for bio-oil with mesoporous molecular sieve catalysts. Appl Biochem Biotechnol 2012; 168:174-82.

[6] Pirouzmand M, Amini M M, Safari N. Immobilization of cobalt phthalocyanine and tetrasulfophthalocyanine onto MCM-41 and MCM-48: effect of immobilization method on catalytic activity. J Brazilian Chem Soci 2013; 24: 1864-70.

[7] Faghihian H, Naghavi M. Synthesis of Amine-functionalized MCM-41 and MCM-48 for removal of heavy metal ions from aqueous solutions. Separation Sci Technol 2014; 49: 214-20.

[8] $\mathrm{Li} \mathrm{X}$, Chen F. Structure and luminescence properties of $\mathrm{Zn}_{2} \mathrm{SiO}_{4}$ : Mn phosphor prepared with MCM-48. Mat Res Bull 2013; 48: 2304-7.

[9] Roskop L, Fedorov D, Gordon M. Diffusion energy profiles in silica mesoporous molecular sieves modeled with the fragment molecular orbital method. Mol Phys 2013; 111: 1622-1629.

[10] Lee JS, Kim D, Choi BH. Hydrogen-rich gas production from ethanol steam-reforming reaction using NiZr-loaded MCM-48 catalysts at mild temperature. Int J Energy Res 2013; 37: 1896-907.

Received: February 23, 2015

(C) Zhixi et al.; Licensee Bentham Open.

This is an open access article licensed under the terms of the (https://creativecommons.org/licenses/by/4.0/legalcode), which permits unrestricted, noncommercial use, distribution and reproduction in any medium, provided the work is properly cited. 